\title{
Consumer acceptance of nutrigenomics-based personalised nutrition
}

\author{
A. Ronteltap ${ }^{1 *}$ J. C. M. van Trijp ${ }^{1}$ and R. J. Renes ${ }^{2}$ \\ ${ }^{1}$ Marketing and Consumer Behaviour Group, Wageningen University and Research Centre, Hollandseweg 1, 6706 KN \\ Wageningen, The Netherlands \\ ${ }^{2}$ Communication Science, Wageningen University and Research Centre, Hollandseweg 1, 6706 KN Wageningen, The Netherlands
}

(Received 6 August 2007 - Revised 3 March 2008 - Accepted 19 March 2008 - First published online 15 May 2008)

Nutrigenomics is a new and promising development in nutritional science which aims to understand the fundamental molecular processes affected by foods. Despite general agreement on its promise for better understanding diet-health relationships, less consensus exists among experts on the potential of spin-offs aimed at the consumer such as personalised nutrition. Research into consumer acceptance of such applications is scarce. The present study develops a set of key hypotheses on public acceptance of personalised nutrition and tests these in a representative sample of Dutch consumers. An innovative consumer research methodology is used in which consumers evaluate short films which are systematically varied scenarios for the future of personalised nutrition. Consumer evaluations of these films, which are pre-tested in a pilot study, allow a formal test of how consumer perceptions of personalised nutrition drive consumer acceptance and through which fundamental psychological processes these effects are mediated. Public acceptance is enhanced if consumers can make their genetic profile available free at their own choice, if the actual spin-off products provide a clearly recognisable advantage to the consumer, and are easy to implement into the daily routine. Consumers prefer communication on nutrigenomics and personalised nutrition by expert stakeholders to be univocal and aimed at building support with consumers and their direct environments for this intriguing new development. Additionally, an exploratory segmentation analysis indicated that people have different focal points in their preferences for alternative scenarios of personalised nutrition. The insights obtained from the present study provide guidance for the successful further development of nutrigenomics and its applications.

Nutrigenomics: Personalised nutrition: Psychological processes: Consumer research

Food intake, or more specifically nutrient exposure, is a key environmental factor that affects health status and performance $^{(1)}$. Since their origination, nutritional sciences have shaped our understanding of optimal levels and combinations of nutrients for health maintenance. Until recently, the focus has been on the discovery of substances in the diet and the mechanisms through which they function ${ }^{(2)}$, resulting in, for example, recommended daily intakes for various nutrients. As people consume foods rather than nutrients, this advice has been translated into food choice recommendations (for example, the Food Guide Pyramid), which are to a large part assumed to be suitable for the entire population ${ }^{(3)}$, with the exception of specific recommendations for groups such as the elderly, pregnant women, infants, or athletes.

Despite its paramount importance for public health in general, limitations of this population-based approach are clearly demonstrated by the substantively different responses individuals can show to a given $\operatorname{diet}^{(4,5)}$. Inspired by the successful completion of the Human Genome Project ${ }^{(6,7)}$, some have argued that nutrition research is now at the verge of a revolution, moving beyond general dietary recommendations towards personalised dietary advice ${ }^{(2,5,8)}$. The line of reasoning is as follows: (1) gene expression and metabolic responses at the cellular level underlie health status, (2) gene expression and metabolic responses are the result of an interaction between genotype and environment (including nutrients), and thus (3) understanding the gene-nutrient interactions might open up the way for personalised nutrient intake recommendations based on an individual's genetic constitution. In scientific terms, understanding the fundamental molecular and metabolic processes affected by foods (nutrigenomics) not only leads to insight into the mechanisms of health and disease, but can also enhance the predictive validity of assessing the genetic make-up for susceptibility to health and disease (nutrigenetics).

Hence, personalised nutrition for individual health management, disease prevention and performance improvement is a potentially promising deliverable from the genomics revolution in nutritional sciences ${ }^{(3)}$. It might provide individuals at high risk for metabolic diseases with specific nutritional advice, thereby maximising the efficacy of preventive measures ${ }^{(9)}$. Scholars in the field, however, differ considerably in their optimism for these personalised diets for the overall population to emerge. Critical considerations about the promising future of personalised nutrition have been formulated from various angles and seem to cluster around three themes.

First, scientific and technological drawbacks of personalising nutrition have been expressed. The fact that genetic information, together with better early detection methods, can add 
to disease prevention is not disputed, but personalised nutrition as a goal is expected to be far ahead in the future ${ }^{(4)}$. Present limitations include our incapacity to define optimal health or its key early biomarkers, and the necessity of large cohort studies which are hampered by the massive amount of phenotypic, genotypic, nutritional and other lifestyle information needed ${ }^{(4)}$. Furthermore, as the genome, health, disease and the diet all are very complex and interactive, causality of certain genetic variations for disease will be difficult to prove and reproducibility of results a struggle (M Katan, unpublished results). A technical hurdle that needs to be overcome is the high standards nutrigenomic foods should meet such as controlled ingredient composition, the ability to be integrated into many food forms, good sensory qualities, and so on ${ }^{(10)}$.

Second, the possibilities for personalised nutrition are questioned from a marketing perspective. Genetics-based personalised nutrition is not likely to reach the mainstream food market any time soon, as for the customer its benefits are currently outweighed by its costs in terms of privacy protection. Also, for food companies the additional costs of production, marketing and distribution of personalised products for increasingly small consumer segments are not accountable yet $^{(11)}$. Much of current segmentation in the food market is based on phenotypic information, so the marketing potential of genotype-personalised nutrition should be assessed by examining its added value over phenotype as the segmentation basis. Crucial are the predictive ability of the genotype for disease development, and the extent to which the effect of genes can be altered by nutrition. Both seem to be limited at this point in time, especially for multi-factorial diseases such as diabetes and obesity ${ }^{(11,12)}$.

Third, consumer acceptance of nutrigenomics and personalised nutrition is under discussion. Nutrigenomics may raise consumer worries regarding the rather instrumental approach to foods - generally an intimate part of people's daily lives with an important hedonic value ${ }^{(8)}$. Furthermore, perceived unnaturalness of (nutri-)genomics technology, privacy issues and control over sensitive information may become sources of concern. Research among Canadian consumers showed that genomics related to food evoked strong associations with genetic modification of crops and foods, for example, Golden Rice ${ }^{(13)}$. Given the current status of other technologies somehow related to genes in Europe (for example, plant biotechnology and stem cell research) $)^{(9)}$, such associations might not be a good omen for public acceptance of nutrigenomics and personalised nutrition.

Consumer acceptance of personalised nutrition has received very limited research attention ${ }^{(11)}$. This is not surprising given the fact that it is unclear how nutrigenomics spin-offs such as personalised nutrition will take shape exactly. At the same time, incorporating consumer preferences and concerns in the early stages of the new product development process has been identified as a critical success factor for technology ${ }^{(14)}$ and new product development ${ }^{(15)}$. So, anticipatory consumer research can help shape the development of the technology to optimise potential spin-offs.

The present study takes a consumer research approach in the context of genomics-based personalised nutrition. Appreciating that the specific characteristics of this new technology have not yet crystallised out, the present study takes more abstract consumer perceptions as its starting point This is consistent with temporal construal theory ${ }^{(16,17)}$, which shows that in their evaluation processes consumers tend to represent situations that are psychologically more distant in time at a more abstract level. Hence, representing potential futures of personalised nutrition in concrete features would not fit with how people conceive of and evaluate them. Building on previous research ${ }^{(18)}$, we investigate the effects of consumer perceptions of personalised nutrition on preference as a measure of acceptance, and through which mechanisms these effects come about. The structure of the paper is as follows. First, using the personalisation and innovation literature we build a conceptual framework from which we develop specific hypotheses. We then test the hypotheses in a largescale consumer study using an innovative research approach. Besides the effects of consumer perceptions of personalised nutrition on preference, we investigate whether distinct consumer groups can be identified with respect to their preferences for personalised nutrition. Results are described and interpreted, and we conclude with implications for the nutrigenomics field.

\section{Theoretical background}

Personalised nutrition constitutes an innovation in the food market. Not only does it reflect the state of the art in nutritional sciences called nutrigenomics, it is also in line with the trend of personalisation in food marketing more generally ${ }^{(10)}$. In many different domains personalisation, defined as the process of adjusting marketing offerings to the identified needs of customers ${ }^{(11)}$, is considered a promising strategy as it adds value to both the customer and the supplier. Value to customers is achieved by a better match of offerings to their idiosyncratic rather than average need structures, and to suppliers by increased price premiums and customer loyalty, and by differentiation from competitors that still focus on mass marketing ${ }^{(19)}$

As to the current personalised nutrition market, two types of products are of interest: diagnostic tests and products based on those tests, be it nutritional advice or food products ${ }^{(20)}$. Various companies are selling DNA-based tests at the moment, some of them also offering dietary supplements or even personalised behavioural recommendations based on their genetic make-up and current eating and lifestyle habits. Due to the current state of science, this dietary advice is rather general in nature and does not provide extensive guidelines about what to eat and what to avoid. To the best of our knowledge, personalised food products based on consumers' DNA are not yet marketed. Truly personalised nutrition is still years ahead of us, and there is no shared view about the future of personalised nutrition, as evidenced by the spectrum of speculations. One possibility is put forward by Joost et al. ${ }^{(9)}$, expecting that personalised nutrition will not be using full, individual genomic information, but will rather be targeted at families. A second operationalisation could be the production of functional foods, nutraceuticals, and supplements with improved substantiation of health claims using genomic knowledge ${ }^{(21)}$. The most dramatic example of personalisation is described by Sutton ${ }^{(10)}$ as the use of point-of-sale technologies where a product (for example, a beverage) could be prepared using a combination of ingredients to suit an individual's genotype. 


\section{Consumer perceptions}

As there is still no agreement on how personalised diets will take form, it makes no sense to investigate consumer acceptance at the level of concrete descriptions. Following the principles of temporal construal theory ${ }^{(16)}$, it is more sensible to use consumer perceptions at a more abstract level for understanding acceptance at this point in time. Consumer acceptance of innovations, such as personalised nutrition, can be partly explained by consumer characteristics, the perceived characteristics of the innovation, and the communication that accompanies the innovation $^{(22)}$.

Hypothesis 1. As to communication, several aspects are of particular interest. Nutrigenomics and personalised nutrition are new and unknown phenomena, which makes consumers more dependent on how and what experts communicate about them. Concerning how they are communicated, objects or events can be described in either positive or negative wording while representing objectively equivalent descriptions. This is called attribute framing and the consensus finding is that positive frames lead to more positive object evaluations than those with a negative framing ${ }^{(23)}$. In the present context, nutrigenomics-based personalised nutrition may be communicated positively in terms of health and performance enhancement at later life stages, or in terms of a reduction of (risk of) disease. Our hypothesis 1 is: 'Compared with negatively framed communication, positively framed communication about personalised nutrition will have a positive effect on consumer acceptance'.

Hypothesis 2. Whereas framing is about how personalised nutrition is being positioned in the market place, another aspect of communication is what is being communicated. Previous research has suggested that in general, receiving conflicting information from different sources would lead to social uncertainty ${ }^{(24,25)}$. People prefer consensus messages, even when they are ambiguous, to conflicting ones ${ }^{(26)}$. Therefore, we expect that a high level of agreement among experts communicating about nutrigenomics and personalised nutrition will enhance consumer acceptance of personalised nutrition. Hypothesis 2 is: "Agreement among experts about the promise of personalised nutrition will have a positive effect on consumer acceptance'.

Hypotheses 3 and 4 . In terms of innovation characteristics, of the many features that have been studied previously, perceived usefulness and ease of use are consistently reported as the strongest determinants of public acceptance of innovation $^{(27)}$. This is also confirmed in the rich literature on the Technology Acceptance Model ${ }^{(28,29)}$. Perceived usefulness is defined as the degree to which an individual believes that using an innovation is beneficial for achieving desired goals. Translated to personalised nutrition, it is the extent to which consumers perceive personalised nutrition to deliver benefits, either to themselves or to another group in society. If personalised nutrition is perceived to be personally relevant and useful to the consumer, this will lead to more rapid adoption of the innovation $^{(22)}$. Also, previous research has shown that acceptance of nutrigenomics products and services may be hampered by consumers' suspiciousness towards commercial interests ${ }^{(11)}$, so we expect that (hypothesis 3 ) 'If personalised nutrition is perceived to be personally relevant and useful in delivering benefits to the consumer, this will have a positive effect on consumer acceptance' and (hypothesis 3a) 'If personalised nutrition is perceived to deliver benefits primarily to industry, this will have a negative effect on consumer acceptance'.

Ease of use expresses the extent to which an innovation is perceived to be difficult to understand and use. In terms of personalised nutrition, ease of use stands for the amount of effort people have to invest to implement personalised nutrition in their daily lives. Think, for example, of the family dinner - if nutrigenomics actually leads to individualised meals, this implies quite some extra work at the household level. Similarly to usefulness, perceived ease of use increases the speed of adoption of an innovation ${ }^{(22)}$. Hypothesis 4 is 'If personalised nutrition is perceived as easy to use and implement in lifestyle, this will have a positive effect on consumer acceptance'.

Hypothesis 5. In the context of genomics-based personalised nutrition, one factor of particular importance is the sensitivity of genetic information in relation to privacy concerns. In order to draw up personalised dietary advice based on a person's genes, it is inevitable to have his or her genetic make-up profiled. A person's genetic make-up is personal, stable over time, and may indicate susceptibility for various disorders. Because DNA samples can be held indefinitely, the risk exists that they will be used for purposes other than those for which they were gathered. Genetic information is potentially interesting to several third parties, for example insurance companies, which might use it to deny insurance policies, employers, who can use it to screen potential employees, or the government, who can use it for screening and health promotion purposes. Hence, consumers may be reluctant to make that necessary genetic information accessible. This may induce a reduction of consumers' (perceived) freedom of choice. Freedom of choice, or autonomy, has been identified as an important basic need for the wellbeing of all people, regardless of sex, group or culture ${ }^{(30)}$. Furthermore, reactance theory states that threats to freedom reduce the effectiveness of social influence and create resistance to persuasion (see, for example, Silvia ${ }^{(31)}$ ). So we anticipate that (hypothesis 5): 'If consumers are allowed freedom to choose to have their genes profiled, this will have a positive effect on consumer acceptance for personalised nutrition'.

To summarise, we identified five consumer perceptions of personalised nutrition that we expect to be important for consumer acceptance. These factors are in line with previous research among expert stakeholders in the field of nutrigenomics that identified inhibiting and promoting factors for the development of nutrigenomics ${ }^{(32)}$.

\section{Psychological processes}

The consumer perceptions of personalised nutrition exert their effect on consumer acceptance through an identified set of psychological processes that determine consumer acceptance of food innovations more generally. This set of psychological constructs consists of cost-benefit assessment, perceived risk and uncertainty, perceived behavioural control and the subjective norm ${ }^{(18)}$. The trade-off between costs and benefits stems from the traditional economic approach to acceptance of technological developments in society ${ }^{(33)}$ and is also prominent in the attitude literature as the pros and cons of conducting the behaviour $^{(34)}$. Behaviours that have a positive benefit:cost ratio are more likely to be engaged in. In contrast to other 
innovations, foods are actually ingested into the human body ${ }^{(35)}$, which makes them very prone to generate perceptions of risk and uncertainty. Whether a person believes he or she can actually perform the behaviour necessary for innovation acceptance is called perceived behavioural control, which has long been identified as a determinant of behaviour, together with the subjective norm (i.e. whether significant others are likely to endorse the behaviour) ${ }^{(36)}$. These four processes have been proposed to mediate the effects of consumer perceptions of personalised nutrition on consumer preferences and thereby on acceptance (see Fig. 1).

The consensus finding in psychological framing theory ${ }^{(23)}$, namely that positive framing of a message (i.e. using positive rather than negative wording for equivalent options with respect to message content) leads to more positive consumer evaluations than negative framing, is attributed to the fact that positive wording makes accessible in memory a broader range of positive associations and that these positive feelings are subsequently mapped onto evaluations of the message (the valence-consistent shift) ${ }^{(23)}$. In the present context, expressing the benefits of personalised nutrition with a focus on delay of onset and even prevention of disease is more likely to make disease-related associations accessible from memory and hence negative emotions. On the other hand, positive communication about personalised nutrition with an emphasis on maintenance of good health communicated with a clear and simple message on its benefits is more likely to make positive feelings accessible ${ }^{(2)}$. In positive moods consumers are less likely to engage in systematic processing such as cost-benefit analysis ${ }^{(37)}$, and more likely to follow a low elaboration affective route such as through risk and uncertainty perceptions. Hypothesis 6 is 'The positive effect of positively framed communication on preference is primarily mediated by reduced levels of risk and uncertainty'.

As with many influential innovations and nutritional innovations in particular, consumers have very limited ability to assess the true added value to quality of life from personal knowledge. To form beliefs about how credible and beneficial these developments are, they have to rely on information from others $^{(36)}$. In the context of nutrition, direct peers, such as family and friends, are not a very informative source of information, leaving consumers reliant on nutritional experts to advise their decision. In line with Fig. 1, we expect that the effects of expert opinion on the feasibility and desirability of personalised nutrition will exert its effect through the subjective norm: the extent to which relevant others endorse the commitment to personalised diets. If nutritional experts are in agreement about the benefits of personalised nutrition, there will be a consistent effect through the subjective norm. Hypothesis 7 is 'The positive effect of agreement about personalised nutrition among experts on preference is primarily mediated by a directive and positive subjective norm'

Several groups in society may benefit from the transition towards personalised nutrition. From a consumer perspective the benefit directly impacts the cost:benefit ratio. If for the consumer the benefits are perceived to outweigh the costs this will enhance acceptance of personalised diets. On the other hand, usefulness of personalised nutrition may also be expressed as benefits to the industry (a commercial benefit) or to the advancement of nutritional sciences more generally. The distribution of costs and benefits of personalised diets may be skewed; they require an investment (both monetary and non-monetary) on the part of the consumer, while benefits may accrue to other stakeholder groups such as the food industry. Hence, we expect that perceived usefulness in terms of beneficiary stakeholder group will exert its effect primarily through the psychological process of cost-benefit consideration. Hypothesis 8 is 'The positive effect on acceptance of the consumer as main beneficiary of personalised nutrition is primarily mediated by a positive outcome of consideration of benefits $v$. costs'.

In the present case, ease of use is the extent to which personalised diets are perceived as being compatible with current food habits and easy to implement in consumers' existing lifestyles. Whereas usefulness directly relates to the benefits inherent in personalised nutrition, ease of use more directly relates to the perceived (non-monetary) costs of adopting personalised diets. If personalised nutrition integrates smoothly into existing eating habits, it is easy to implement in daily life, which reduces the perceived costs of the innovation.

Film scenes manipulating Psychological processes (M) Outcome (Y) consumer perceptions $(\mathrm{X})$

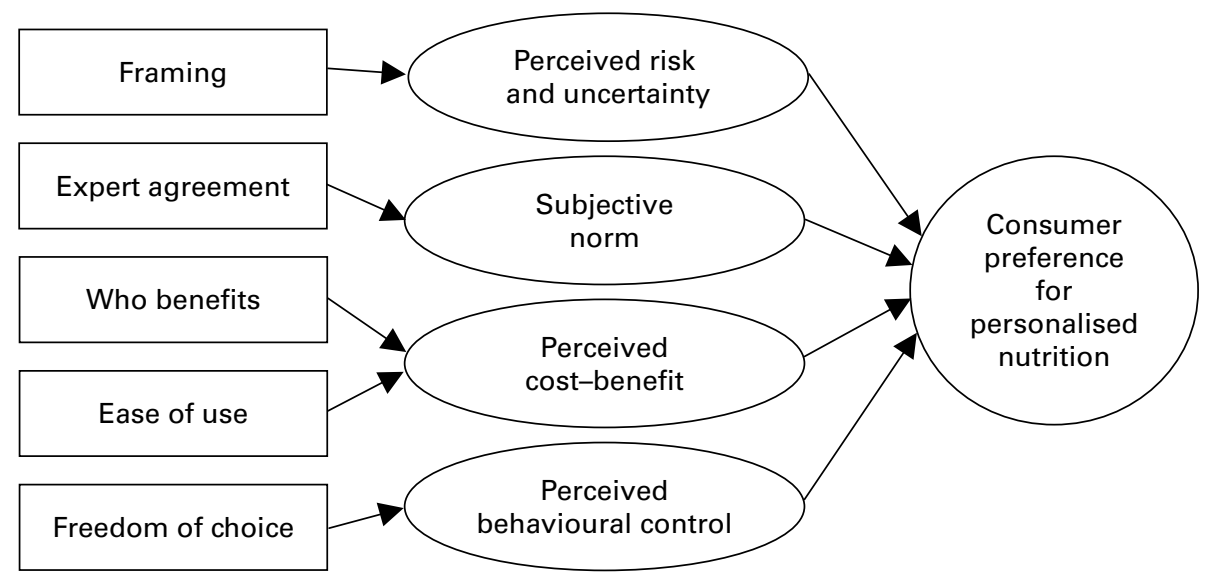

Fig. 1. Theoretical model. 
Hypothesis 9 is 'The positive effect of ease of use on acceptance is primarily mediated by a positive outcome of considerations of benefits $v$. costs'.

As argued previously, the extent to which consumers are free to choose whether or not to make their genetic profile available is expected to be a key determinant of consumer acceptance of personalised nutrition. In general, consumers in Western societies put high value on independence and freedom of choice as this enhances their perception of autonomy ${ }^{(30)}$. In terms of Fig. 1, we therefore hypothesise that freedom of choice for having the genetic constitution profiled and registered (as opposed to being obliged to do so by, for example, the government) will strongly prompt consumer perceptions of the control they have over their behaviour. Hence (hypothesis 10) 'The positive effect of freedom of choice on acceptance is primarily mediated by a higher perception of behavioural control'.

All our hypotheses focus on generic processes to explain how consumer perceptions of personalised diets affect consumer acceptance. However, in these processes, consumers may differ in the extent to which they value each of the perceptions to arrive at a personal acceptability of personalised diets. As to our knowledge there is no previous research on consumer segmentation in acceptance of alternative operationalisations of personalised nutrition, we also conduct an exploratory segmentation analysis. The aim of this segmentation is to explore sensible subgroups of consumers with similar preferences for personalised nutrition operationalisations.

\section{Methodology}

As personalised nutrition is in an early stage of development, consumers may have difficulties imagining it. To provide consumers with an adequate context, we used an innovative research method in which consumers evaluated systematically varied scenarios of how genomics-based personalised nutrition might develop in the future. Inspired by techniques such as information acceleration ${ }^{(38)}$, we provided these scenarios to consumers as short films rather than 'cold' words to enhance the validity of the consumer evaluations.

\section{Stimulus material}

Our model distinguishes between five consumer perceptions, all but one at two levels (in parentheses): message framing (positive $v$. negative), agreement between experts (consensus $v$. dissensus), beneficiary stakeholder group (consumer $v$. science $v$. industry), ease of use (easy $v$. complex), and freedom of choice (freedom $v$. coercion). For each of these levels, concise verbal scripts were written by the authors (see Appendix 1) on the basis of which the Utrecht School of the Arts produced eleven $(4 \times 2+1 \times 3)$ short (average length of $39.5 \mathrm{~s}$ ) film scenes. Before assembling these film scenes into systematically varied five-scene films (the number of consumer perceptions), they were pre-tested in a pilot study.

\section{Pilot study}

To verify the validity of the film scenes as experimental manipulations of the different levels of the consumer perceptions, a quantitative pilot study was conducted with a sample of ninety-two respondents $(51 \%$ males, average age 30.5 (SD 6.1) years). Each respondent rated all eleven scenes in randomised order on a set of sixteen items (see Table 1) using nine-point Likert-type scales. Table 1 shows the mean ratings for the relevant items per scene (Full results are available from the corresponding author. Analysis of non-targeted items

Table 1. Consumer perception of personalised nutrition: mean scores for manipulation check items in pilot study*

\begin{tabular}{|c|c|c|c|}
\hline \multirow{2}{*}{$\begin{array}{l}\text { Item (measured on nine-point scales) } \\
\text { Message framing }\end{array}$} & \multicolumn{3}{|c|}{ Levels manipulated in film scenes } \\
\hline & Positive & Negative & \\
\hline Is film focused on achieving positive events? & $8 \cdot 1^{\mathrm{c}}$ & $7 \cdot 5^{\mathrm{d}}$ & \\
\hline Is film focused on preventing negative events? & $6 \cdot 2^{\mathrm{c}}$ & $7 \cdot 2^{\mathrm{d}}$ & \\
\hline Had no trouble imagining the film was real & $7 \cdot 3$ & 6.4 & \\
\hline Agreement & Consensus & Dissensus & \\
\hline Do experts agree? & $7 \cdot 6^{\mathrm{a}}$ & $2 \cdot 4^{\mathrm{b}}$ & \\
\hline Do experts share the same opinion? & $7 \cdot 5^{\mathrm{a}}$ & $1.8^{\mathrm{b}}$ & \\
\hline Had no trouble imagining the film was real & 5.4 & 5.9 & \\
\hline Which group benefits? & Consumer & Science & Industry \\
\hline Do consumers benefit primarily from personalised nutrition? & $7 \cdot 6^{\mathrm{a}}$ & $6 \cdot 8^{\mathrm{a}, \mathrm{b}}$ & $6 \cdot 1^{\mathrm{b}}$ \\
\hline Do scientists benefit primarily from personalised nutrition? & $6 \cdot 8^{\mathrm{C}}$ & $7 \cdot 9^{\mathrm{d}}$ & $6 \cdot 9^{\mathrm{c}}$ \\
\hline Does industry benefit primarily from personalised nutrition? & 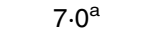 & 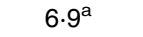 & $8 \cdot 2^{\mathrm{b}}$ \\
\hline Had no trouble imagining the film was real & $8 \cdot 0$ & $7 \cdot 2$ & $6 \cdot 6$ \\
\hline Ease of use & Easy & Complex & \\
\hline How much effort does personalised nutrition cost? & $3.0^{\mathrm{a}}$ & $6 \cdot 8^{\mathrm{b}}$ & \\
\hline How easy is personalised nutrition to implement in daily life? & 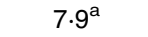 & 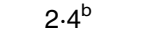 & \\
\hline Had no trouble imagining the film was real & $6 \cdot 3$ & $5 \cdot 9$ & \\
\hline Freedom of choice & Freedom & Coercion & \\
\hline Do consumers have freedom of choice in having genetic data examined? & $6 \cdot 7^{\mathrm{a}}$ & $2 \cdot 8^{\mathrm{b}}$ & \\
\hline Are consumers forced to have genetic data examined? & $3.8^{\mathrm{a}}$ & $7.5^{\mathrm{b}}$ & \\
\hline Had no trouble imagining the film was real & $6 \cdot 4$ & $5 \cdot 3$ & \\
\hline
\end{tabular}

*Differences between mean values were examined per item through $t$ tests or the $F$ test (for Which group benefits? only) with Tukey's honestly significant differences multiple comparison test.

a,b Mean values within a row with unlike superscript letters were significantly different $(P<0.05)$

${ }_{\mathrm{c}, \mathrm{d}}$ Mean values within a row with unlike superscript letters were significantly different $(P<0 \cdot 10)$. 
(for example, rating of ease of use for framing manipulation) showed no consistent patterns.). Respondents perceived all scenes as realistic as evidenced by the average score of 6.4 (range 5.3-8.0) on the item 'I had no trouble imagining this film was real'. Table 1 further reveals that the film scenes adequately represented the intended levels of consumer perceptions, although for message framing we found less strong support $(P<0 \cdot 10)$.

These results provided a good basis for use of the filmed material in the main study. The film scenes were combined to form various possible descriptions of the future of personalised nutrition. Each combination of five scenes (one level of each of the five perceptions) will be called a 'profile' from here on. An example of a possible profile in key words is shown below:

The framing of communication to the consumer is positive; There is agreement among stakeholders about the meaningfulness for society;

Scientists are the group that benefits from personalised nutrition;

Personalised nutrition is easy to use for the consumer;

There is no freedom of choice for the consumer.

The ingredients of the full text are provided in Appendix 1.

\section{Data collection procedure}

Design. A systematically varied design was used to determine consumers' preference structure for personalised nutrition. With five scenes, one with three levels and four with two levels, the total number of possible profiles (i.e. different five-scene combinations) would be forty-eight $(3 \times 2 \times 2 \times 2 \times 2)$. To minimise information overload and fatigue, a fractional factorial main-effects design was used to reduce the profiles to eight while maintaining orthogonality of the factors. In marketing research this methodology is known as conjoint analysis and is widely applied both in scientific $^{(39)}$ and commercial studies ${ }^{(40)}$. Based on the fractional factorial design with scene levels, coded as dummy variables, serving as independent variables individual-level linear regression models were estimated across the eight so-called calibration profiles with preference as the dependent variable. The fit of these linear regression models was estimated as the correlation between predicted preferences from the linear regression model with the actual preference ratings provided by the respondent. Predictive validity of the individual level linear regression models was assessed for three so-called hold-out profiles which were also rated on preference by the respondents but not incorporated in the estimation of the regression parameters. Predictive validity with three hold-out profiles can be assessed from the regression model's ability to correctly predict the highest preference from among the three hold-out profiles (percentage of correctly predicted first choice).

The participants were randomly assigned to one of eight blocks, each block having a unique set of hold-out profiles to increase variability in the study. As a warm-up and to familiarise respondents with the task, each respondents first evaluated one standard reference profile before evaluating the eight calibration profiles, and three hold-out profiles, randomly chosen per block. The order of the profiles was randomised per set of eight calibration profiles and per set of three holdout profiles, and scenes within the profiles were shown in random order to prevent predictability and thereby loss of attention of respondents.

Sample. The data were collected between November 2006 and February 2007 by a professional marketing research agency. Respondents were approached by telephone at random and sampled on the basis of their age, sex, education, family size and region of residence, in order to arrive at a quota sample representative of the Dutch population. A total of 643 respondents were invited to visit the nearest of eighteen test facilities to participate in the study, of which 438 respondents $(68 \%)$ successfully finished their participation. Of the remaining 205 respondents, 175 did not show up and thirty experienced technical difficulties with computers used for the research. A comparison between the Dutch population and our sample (see Table 2) with respect to the demographic data shows a good match with some minor differences. The sample distribution is equivalent to the population distribution in terms of $\operatorname{sex}\left(\chi_{(\mathrm{df} 1)}^{2}=0 \cdot 17\right.$; NS $)$ and regional spread $\left(\chi_{\text {(df4) }}^{2}=3 \cdot 27\right.$; NS) but there is a slight under-representation of single-person households $\left(\chi_{(\mathrm{df} 2)}^{2}=34.52 ; P<0.05\right)$ and a slight over-representation $\left(\chi_{(\mathrm{df} 4)}^{2}=54.46 ; P<0.05\right)$ of respondents in the age category 40-64 years and respondents with higher education $\left(\chi_{(\mathrm{df} 2)}^{2}=66.68 ; P<0.05\right)$. However, we have no reason to assume that these small differences would influence the interpretation of the present results.

Protocol. Respondents were invited to one of eighteen test facilities, spread over The Netherlands. After a group introduction, in which the host stressed that the scenarios in the study take place in the future (2015), respondents participated individually on a laptop wearing headsets. They were given on-screen instructions to carefully watch and listen to each

Table 2. Study sample characteristics compared with the Dutch population in 2006

\begin{tabular}{|c|c|c|c|c|}
\hline & $\begin{array}{l}\text { Sample (\%) } \\
\quad(n 416)\end{array}$ & $\begin{array}{c}\text { Population } \\
\text { (\%)† }\end{array}$ & $x^{2}$ & df \\
\hline Sex & & & 0.17 & 1 \\
\hline Male & 48 & 49 & & \\
\hline Female & 52 & 51 & & \\
\hline Age (years) & & & $54 \cdot 46^{\star}$ & 4 \\
\hline$<20$ & 4 & 7 & & \\
\hline $20-39$ & 24 & 33 & & \\
\hline $40-64$ & 54 & 42 & & \\
\hline $65-79$ & 18 & 13 & & \\
\hline$\geq 80$ & - & 4 & & \\
\hline Household size & & & $34.52^{*}$ & 2 \\
\hline One person & 21 & 35 & & \\
\hline Two persons & 41 & 33 & & \\
\hline$>$ Three persons & 38 & 33 & & \\
\hline Education & & & $66 \cdot 68^{*}$ & 2 \\
\hline Low & 20 & 34 & & \\
\hline Middle & 39 & 40 & & \\
\hline High & 41 & 25 & & \\
\hline Nielsen regional spread & & & $3 \cdot 27$ & 4 \\
\hline (1) Three big cities & 15 & 16 & & \\
\hline (2) Rest of West & 34 & 30 & & \\
\hline (3) North & 9 & 10 & & \\
\hline (4) East & 20 & 21 & & \\
\hline (5) South & 22 & 23 & & \\
\hline
\end{tabular}

${ }^{*} P<0.05$.

† Centraal Bureau voor de Statistiek ${ }^{(52)}$ 
scenario and answer questions about the scenarios. It took them on average 69.7 ( $\mathrm{SD} 8.8$ ) $\mathrm{min}$ to complete the test, with a $5 \mathrm{~min}$ break in the middle of the test to prevent severe fatigue. Afterwards, respondents were debriefed and given a monetary compensation for their participation.

\section{Measurements}

As a measure for acceptance, the key dependent variable was preference, measured with a three-item semantic differential scale $(\alpha=0.97)$ based on Bredahl ${ }^{(41)}$ (in $\operatorname{Laros}^{(42)}$ ). End poles of the seven-point semantic differential scales were labelled 'bad-good', 'unappealing-appealing' and 'negative-positive', respectively. For further analysis, the scores on the three items were averaged, the key dependent variable in the present study thus ranging from 1 to 7 . For the psychological processes of cost-benefit assessment, perceived risk and uncertainty, perceived behavioural control and subjective norm, one-item seven-point Likert-type measures were used with end poles labelled 'disagree' (1) and 'agree' (7). The items were selected from previous research (A Ronteltap, JCM van Trijp and RJ Renes, unpublished results) and selected as the best item from their respective multiple-item scales. (In previous research, these multi-items scales showed adequate internal consistency: cost-benefit assessment (three items; $\alpha=0.88$ ), perceived risk and uncertainty (three items; $\alpha=0.73$ ), perceived behavioural control (four items; $\alpha=0.76$ ), subjective norm (two items; $\alpha=0.58$ ).) Risk and uncertainty were measured as two separate constructs, as the internal consistency of the scale combining both was very low. All items are listed in Table 3 .

\section{Data analysis}

Examination of the dataset. Data were examined for any irregularities. Of the 438 respondents, one gave the same answer to all questions, and another nine rated all twelve profiles with the same preference. In addition, their time spent on answering the questions was lower than average. These ten respondents were excluded from further analyses as they did not perform their task seriously. The correlation between the measured and the predicted preference scores for the eight calibration profiles, expressed as Pearson's $R$, was not significant for another twelve cases, meaning that the estimated regression model did not adequately represent those respondents' data. Dropping this group left a final sample of 416 respondents.

Mediation analysis. To examine whether the psychological processes of perceived risk, perceived uncertainty, subjective norm, perceived cost-benefit and perceived behavioural control (denoted $M$ in Fig. 1) mediate the effect of the consumer perceptions (operationalised in film scenes and denoted $\mathrm{X}$ in Fig. 1) on consumer preference for personalised nutrition (denoted $\mathrm{Y}$ in Fig. 1), a standard mediation analysis was performed ${ }^{(43)}$. Perfect mediation is demonstrated if the independent variables (film scenes $\mathrm{X}$ ) exert significant effects on the mediator (psychological processes M) as well as the dependent variable (consumer preference $\mathrm{Y}$ ) but the effect of the independent variable on the dependent variable becomes non-significant when the mediating variable is incorporated as a covariate. If the effect remains significant but the effect size significantly reduces, partial mediation is demonstrated. Mediation is formally tested through a set of regression equations, namely: (1) $Y=f(X)$, (2) $M=f(X)$, and (3) $Y=f(M, X)$, with the size of the regression parameter for the independent variables being compared between models (1) and (3). Note that $\mathrm{X}$ is measured as dummy variables $(0-1)$, and $\mathrm{M}$ and $\mathrm{Y}$ on a scale ranging from 1 to 7 .

Heterogeneity in consumer preference. To explore the possibility that consumers may not be homogeneous with regard to their preference structure for different operationalisations of personalised nutrition as evidenced in the filmed scenarios $(Y=f(X))$, a finite-mixture regression model was estimated following the principles of market segmentation proposed by Wedel \& Kamakura ${ }^{(44)}$. Finite-mixture modelling provides techniques to partition data into homogeneous subgroups and simultaneously perform regression analyses within each group. The software package GLIMMIX 2 was used, which allows for the simultaneous estimation of respondent segments and regression models to explain preference per segment. Preference ratings were centred to prevent a segmentation based on the value of the mean. As GLIMMIX gives probabilities of respondents' membership of segments instead of strictly assigning them to one particular group, the posterior probabilities were used to assign respondents

Table 3. Overview of items used in the main study

\begin{tabular}{|c|c|}
\hline Outcome measures and psychological processes & Items \\
\hline \multicolumn{2}{|l|}{ Outcome measure $(\mathrm{Y})$} \\
\hline Preference & $\begin{array}{l}\text { I think the development outlined in the film is: (1) bad-good; } \\
\text { (2) unappealing-appealing; (3) negative-positive }\end{array}$ \\
\hline \multicolumn{2}{|l|}{ Psychological processes (M) } \\
\hline Perceived cost-benefit considerations & $\begin{array}{l}\text { If I consider all pros and cons of the development outlined in the film, } \\
\text { I am positive about it (disagree-agree) }\end{array}$ \\
\hline Perceived risk & $\begin{array}{l}\text { I have the feeling that the development outlined in the film brings about a } \\
\text { lot of risk (disagree-agree) }\end{array}$ \\
\hline Perceived uncertainty & $\begin{array}{l}\text { My feelings tell me that the development outlined in the film leads to high } \\
\text { uncertainty (disagree-agree) }\end{array}$ \\
\hline Subjective norm & $\begin{array}{l}\text { Most people who are important to me would be positive about the development } \\
\text { outlined in the film (disagree-agree) }\end{array}$ \\
\hline Behavioural control & $\begin{array}{l}\text { If the future develops as in the film, I will have full control over the decision to } \\
\text { participate in it (disagree-agree) }\end{array}$ \\
\hline
\end{tabular}


to one segment exclusively for further examination of the segments.

\section{Results}

An average Pearson's $R$ of 0.951 (range 0.656-1.000; SD 0.062 ) between model-predicted and actual preferences showed an excellent fit of the model for the calibration profiles. In addition, the correlation coefficient between the average measured preference for all profiles included in the study and the average predicted preference was 0.96 , so the conjoint model was also able to predict consumer preference for all profiles at the group level very well. The predictive ability of the conjoint model for the hold-out profiles on an individual level, measured by the percentage correctly predicted first choice, was $47.6 \%$, which is significantly higher than the $33.3 \%$ correct predictions that could be expected based on chance. (The percentage correctly predicted first choice measure expresses the extent to which the model is able to correctly predict which of the three hold-out profiles rated by each respondent is preferred most. Because of the presence of ties in both the actual and predicted preference scores, all first-choice indices have been adjusted to allow for multiple first-choice hits. For example, if a respondent prefers two profiles most and equally, while the model predicts only one of those two profiles to be preferred most, the first-hit index was recorded as 0.5 instead of 1.0 (similar to Green \& Schaffer $\left.{ }^{(45)}\right)$.) These results show that the conjoint model performed very well on an aggregate level and acceptably on an individual level.

\section{Mediation by psychological processes}

The results of the mediation analysis are displayed in Table 4, the columns indicating the different models estimated in the steps of the mediation analysis. (A condition for mediation is that the consumer perceptions and the mediators (the constructs) are correlated. A multivariate analysis of variance resulted in models that explained $13.3 \%$ of variance in cost-benefit perceptions, $3.6 \%$ of variance in risk perception, $2.5 \%$ of variation in perceived uncertainty, $10.9 \%$ of variance in subjective norm, and $29.2 \%$ of variance in perceived behavioural control. All effects of the consumer perceptions on the constructs for which we formulated specific hypotheses (hypotheses 6-10) were significant at $P<0 \cdot 05$, except for all effects of message framing.)

In model $1(\mathrm{Y}=\mathrm{f}(\mathrm{X}))$, preference was explained by dummies of the film scenes manipulating the consumer perceptions $\left(R^{2} 15 \%\right)$. All perceptions except framing contributed significantly to explaining preference, with freedom of choice as the strongest contributor. As hypothesised, consensus among experts $(b=0.326)$, benefits for consumers $(b=0.275)$ or science $(b=0.291)$, personalised nutrition being easy to use $(b=0 \cdot 281)$, and consumer freedom of choice $(b=0.822)$ had a positive effect on preference compared with their counterpart-levels $(P<0 \cdot 01)$. This implies that we found no support for hypothesis 1, strong support for hypotheses 2 to 4 , and very strong support for hypothesis 5 .

The second model $(Y=f(M))$, exploring the effects of the psychological constructs on preference, explained $66.5 \%$ of variance in preference. A positive outcome of benefits

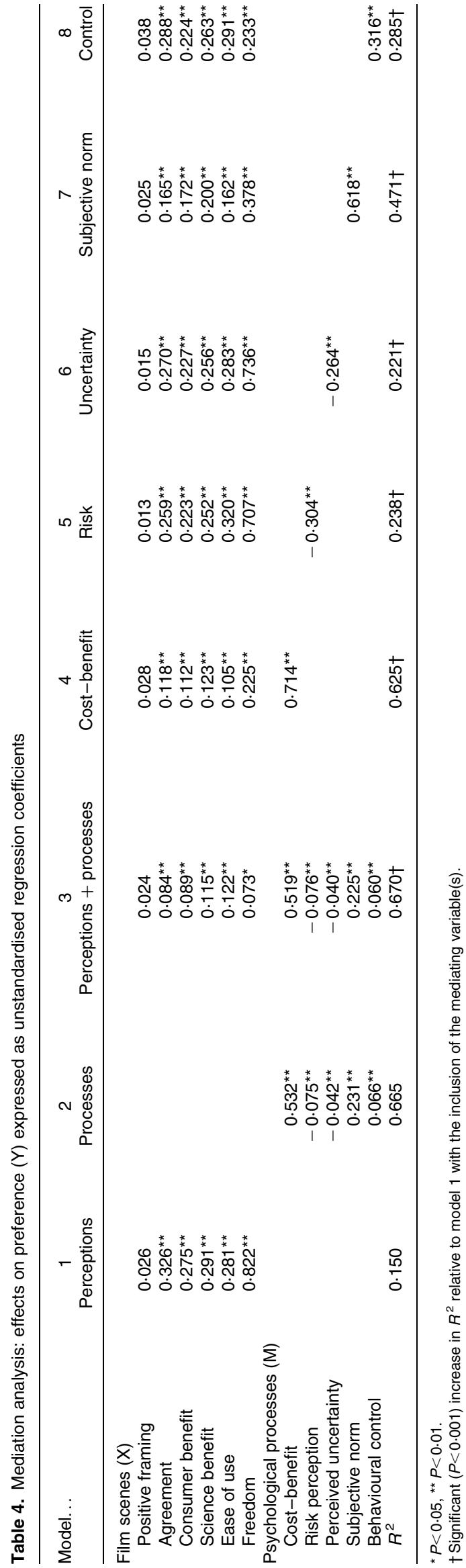


against costs $(b=0.532)$, a strong perception of the subjective norm $(b=0.231)$ and a high behavioural control perception $(b=0.066)$ influenced preference positively, while risk $(b=-0.075)$ and uncertainty $(b=-0.042)$ perceptions affected preference negatively $(P<0 \cdot 01)$. All processes contributed significantly, but consideration of costs and benefits was clearly the strongest contributor. Model 2 lent strong empirical support to the conceptual model used in the present study (Fig. 1).

Model $3(\mathrm{Y}=\mathrm{f}(\mathrm{X}, \mathrm{M}))$ included both the film scenes and the psychological constructs to explain preference. The explained variance of this model was $67.0 \%$, and all predictors had a significant effect at 5\%, except for message framing. The considerable drop in regression coefficients of the film scene perceptions in model 3 compared with model 1 showed (partial) mediation of the film scene perceptions by the psychological constructs. (There is no formal statistical test to assess the size of the reduction in the regression parameters. This is a qualitative judgment, based on the ratio of the direct effect without $v$. with inclusion of the mediating construct.) To examine which of the constructs mediates which film scene perception effect (hypotheses 6-10), the models $4-8$ were estimated (see Table 4). In model 4 , the consideration of costs and benefits was added to the film scenes as predictor of preference. In model 5, risk perception was added, in model 6 perceived uncertainty, in model 7 subjective norm, and in model 8 perceived behavioural control.

The effect of message framing on preference was not significant, but as hypothesised (hypothesis 6), its regression coefficient decreased when risk (model 5) or uncertainty (model 6) were added. Therefore, we found directional (but insignificant) support for hypothesis 6 . The effect of agreement among experts was expected to be mediated primarily by the subjective norm, which was indeed the case (see model 7), so hypothesis 7 is supported. Moreover, model 4 showed that cost-benefit considerations also mediated the effect of agreement partially. In support of hypothesis 8, the effect of who benefits from personalised nutrition was mediated by a trade-off between costs and benefits (see model 4). Furthermore, the positive effect of the consumer as the main beneficiary of personalised nutrition was also partly mediated by the subjective norm (model 7). In accordance with hypothesis 9, the effect of ease of use was mediated by a positive outcome of the trade-off between benefits and costs, but also by the subjective norm. The positive effect of freedom of choice was mediated by a higher perception of behavioural control, as shown in model 8, lending support for hypothesis 10 . This effect too was partially mediated by cost-benefit considerations, and, to a lesser extent, by the subjective norm.

In summary, we found strong support for all hypotheses except those related to message framing. Additionally, we found that many of the effects were also mediated by costbenefit considerations, the most dominant of the psychological processes that determine consumer acceptance.

\section{Heterogeneity in consumer preferences}

Multivariate normal mixture regression models with two to seven classes were fitted, with the film scenes as manipulations of consumer perceptions as predictors for preference.
We ran the mixture regression model with ten different start values to avoid solutions at local optima. The solutions were very stable. We selected the six-class solution which minimises the values of the consistent Akaike information criterion and Bayesian information criterion. Table 5 shows the estimated regression coefficients for each of the six segments, expressed relative to their reference level. The segments are described by their mean demographics and the relative importance the segments attach to the psychological constructs mediating the effect on preference. The first segment consisted of nearly $6 \%$ of the sample, for which preferences for personalised nutrition were hardly influenced by any of the consumer perceptions. Also, none of the mediating psychological processes explained their preferences $\left(R^{2} 0.027\right.$; NS). Consumers in this segment have higher age on average (mean age 59 years), are mainly living in two-person households and have a relatively low education level. Preferences in segment two were significantly influenced by almost all consumer perceptions manipulated in the film scenes and particularly ease of use and freedom of choice. This segment was not driven by convenience, as ease of use actually strongly $(b=-0.998)$ distracted from their preferences. For this segment, perceived risk was a significant predictor of preference. The segment's size was $16 \%$, and it consisted of relatively few people with a one-person household. The third segment $(21 \%$ of the sample) attached a very high importance to ease of using nutrigenomics, and contained even fewer people who live alone. Cost-benefit trade-off was the dominant psychological construct for them. Segment 4 contained more males than females, and their preferences were very strongly driven by freedom of choice. Behavioural control was the psychological construct driving their preferences relatively strongly. This segment was characterised by a relatively high level of education. Compared with the total population, segment 5 was relatively insensitive to agreement among experts, ease of use and freedom of choice. Preferences of this segment, with a small majority of women, were poorly accounted for both in terms of consumer perceptions manipulated in the film scenes $\left(R^{2} 0.035\right)$ and mediating psychological constructs $\left(R^{2} 0 \cdot 143\right)$. Compared with the other segments, the profile of the last and largest $(27 \%)$ segment deviates least from the overall population except that it consisted mainly of females with a relatively high level of education who attached an above average importance to behavioural control in their preference formation.

\section{Discussion}

Despite widespread consensus on the potential of nutrigenomics research for understanding the mechanisms of health as affected by the diet, less agreement exists when it comes to the feasibility of nutrigenomics-based consumer applications ${ }^{(32)}$. Scientific research on consumer acceptance of nutrigenomics applications is scarce, which is expectable given the early stage the development of the field is in. There have been some commercial pieces of research into consumer responses to nutrigenomics and personalised nutrition from the USA, conducted by the Institute for the Future $^{(20,46,47)}$ and the International Food Information Council $^{(48,49)}$, together with the commercial agency Cogent Research. However, early insight into consumer acceptance 
Table 5. Six-segment solution†

\begin{tabular}{|c|c|c|c|c|c|c|c|c|c|}
\hline & Overall & Segment 1 & Segment 2 & Segment 3 & Segment 4 & Segment 5 & Segment 6 & Test statistic & df \\
\hline \multicolumn{10}{|l|}{ Subjects } \\
\hline$n$ & 416 & 17 & 67 & 86 & 71 & 64 & 111 & & \\
\hline$\%$ & & $4 \cdot 1$ & $16 \cdot 1$ & $20 \cdot 7$ & $17 \cdot 1$ & $15 \cdot 4$ & $26 \cdot 7$ & & \\
\hline \multicolumn{10}{|l|}{ Scenes (b) } \\
\hline Positive framing & 0.026 & -0.013 & $0.383^{\star \star}$ & -0.098 & -0.071 & -0.021 & -0.005 & & \\
\hline Agreement & $0.326^{* *}$ & -0.022 & $0.633^{\star *}$ & $0.349^{\star \star}$ & $0.364^{\star \star}$ & $0.064^{*}$ & $0.279^{\star *}$ & & \\
\hline Consumer benefit & $0.275^{\star \star}$ & 0.000 & 0.211 & $0.508^{\star *}$ & $0.475^{\star \star}$ & $0 \cdot 103^{\star *}$ & $0 \cdot 129^{\star}$ & & \\
\hline Science benefit & $0.291^{\star \star}$ & -0.025 & $0.540^{\star \star}$ & $0.337^{\star \star}$ & $0.422^{\star \star}$ & $0.095^{\star \star}$ & $0 \cdot 169^{\star \star}$ & & \\
\hline Ease of use & $0.281^{\star *}$ & -0.012 & $-0.998^{\star \star}$ & $1.589^{* \star}$ & $0.401^{\star *}$ & 0.021 & $0 \cdot 145^{\star \star}$ & & \\
\hline Freedom of choice & $0.822^{\star *}$ & 0.010 & $0.916^{\star \star}$ & $0.352^{\star *}$ & $2 \cdot 835^{\star \star}$ & 0.030 & $0.437^{\star \star}$ & & \\
\hline$R^{2} \ddagger$ & 0.150 & 0.053 & 0.352 & 0.345 & 0.681 & 0.035 & 0.129 & & \\
\hline Time spent (min) & $69 \cdot 77$ & $72 \cdot 34^{\mathrm{a}, \mathrm{b}}$ & $71.08^{\mathrm{a}}$ & $71.39^{\mathrm{a}}$ & $67.94^{\mathrm{b}}$ & $68 \cdot 73^{a, b}$ & $69 \cdot 09^{a, b}$ & $F=2 \cdot 14$ & 5 \\
\hline Age (years) & 48.9 & $58 \cdot 7^{\mathrm{a}}$ & $48 \cdot 7^{b}$ & $49 \cdot 5^{\mathrm{b}}$ & $46 \cdot 9^{b}$ & $48 \cdot 7^{\mathrm{b}}$ & $48 \cdot 7^{\mathrm{b}}$ & $F=1.47$ & 5 \\
\hline $\operatorname{Sex}(\%)$ & & & & & & & & $\chi^{2}=36 \cdot 90^{\star \star}$ & 5 \\
\hline Male & $48 \cdot 3$ & 52.9 & $47 \cdot 8$ & 53.5 & $57 \cdot 7$ & $45 \cdot 3$ & $39 \cdot 6$ & & \\
\hline Female & $51 \cdot 7$ & $47 \cdot 1$ & $52 \cdot 2$ & 46.5 & $42 \cdot 3$ & 54.7 & $60 \cdot 4$ & & \\
\hline Household size (\%) & & & & & & & & $\chi^{2}=161 \cdot 7^{\star \star}$ & 10 \\
\hline 1 & $21 \cdot 2$ & $25 \cdot 0$ & $19 \cdot 4$ & $12 \cdot 8$ & 22.5 & $28 \cdot 1$ & $23 \cdot 4$ & & \\
\hline 2 & $40 \cdot 7$ & 62.5 & $40 \cdot 3$ & $40 \cdot 7$ & $40 \cdot 8$ & 34.4 & 41.4 & & \\
\hline$\geq 3$ & $38 \cdot 1$ & 12.5 & $40 \cdot 3$ & $46 \cdot 5$ & $36 \cdot 6$ & 37.5 & 35.1 & & \\
\hline Nielsen region (\%) & & & & & & & & $\chi^{2}=157 \cdot 4^{\star \star}$ & 20 \\
\hline Three big cities & $15 \cdot 1$ & $11 \cdot 8$ & 11.9 & $12 \cdot 8$ & $16 \cdot 9$ & $15 \cdot 6$ & $18 \cdot 0$ & & \\
\hline Rest of West & 33.9 & $17 \cdot 6$ & $37 \cdot 3$ & 31.4 & $40 \cdot 8$ & $40 \cdot 6$ & 27.9 & & \\
\hline North & $9 \cdot 4$ & 11.8 & $10 \cdot 4$ & 11.6 & $14 \cdot 1$ & $3 \cdot 1$ & $7 \cdot 2$ & & \\
\hline East & $20 \cdot 2$ & $29 \cdot 4$ & $20 \cdot 9$ & $19 \cdot 8$ & 9.9 & $20 \cdot 3$ & $25 \cdot 2$ & & \\
\hline South & 21.4 & 29.4 & 19.4 & $24 \cdot 4$ & $18 \cdot 3$ & $20 \cdot 3$ & 21.6 & & \\
\hline Education (\%) & & & & & & & & $\chi^{2}=163 \cdot 9^{\star \star}$ & 10 \\
\hline Low & $19 \cdot 6$ & 21.4 & $16 \cdot 7$ & $22 \cdot 8$ & $16 \cdot 4$ & $21 \cdot 7$ & $19 \cdot 4$ & & \\
\hline Middle & $39 \cdot 2$ & $64 \cdot 3$ & $45 \cdot 0$ & $39 \cdot 2$ & 34.4 & 36.7 & 36.7 & & \\
\hline High & $41 \cdot 1$ & $14 \cdot 3$ & $38 \cdot 3$ & $38 \cdot 0$ & $49 \cdot 2$ & 41.7 & 43.9 & & \\
\hline \multicolumn{10}{|c|}{ Psychological constructs (b) } \\
\hline Cost-benefit & $0.532^{\star \star}$ & -0.114 & $0.557^{\star \star}$ & $0.613^{\star \star}$ & $0.546^{\star \star}$ & $0.227^{\star \star}$ & $0.478^{\star \star}$ & & \\
\hline Risk & $-0.075^{\star \star}$ & -0.058 & $-0.132^{\star \star}$ & $-0.076^{\star}$ & -0.027 & -0.076 & $-0.064^{\star}$ & & \\
\hline Uncertainty & $-0.042^{\star \star}$ & -0.008 & -0.010 & -0.039 & $-0.049^{\star}$ & $-0.099^{\star}$ & -0.012 & & \\
\hline Subjective norm & $0.231^{\star \star}$ & -0.038 & $0.212^{\star \star}$ & $0 \cdot 163^{\star \star}$ & $0 \cdot 259^{\star \star}$ & $0.178^{\star \star}$ & $0.191^{\star \star}$ & & \\
\hline Behavioural control & $0.066^{\star \star}$ & 0.115 & 0.050 & 0.039 & $0.148^{\star \star}$ & 0.064 & $0 \cdot 117^{\star \star}$ & & \\
\hline$R^{2}$ & 0.665 & 0.027 & 0.672 & 0.604 & 0.870 & 0.143 & 0.444 & & \\
\hline
\end{tabular}

a,b Mean values within a row with unlike superscript letters were significantly different $(P<0.05)$ (least significant difference multiple comparison test).

${ }^{\star} P<0.05,{ }^{\star *} P<0.01$.

†Differences between segments were tested with $F$ tests for continuous variables (time spent, age) and $\chi^{2}$ tests for nominal (sex, Nielsen region) and ordinal (education) variables.

$\ddagger$ As GLIMMIX does not provide $R^{2}$ values per segment, these were calculated externally based on exclusive segment membership.

is important, as it can inform the further development of the technology, its positioning in the consumer domain and the communication surrounding it. The present study is an early attempt to get to grips with consumer understanding of personalised nutrition.

Research on consumer acceptance of future applications is complicated by the fact that consumers lack an adequate frame of reference and tend to think about future situations in abstract, less elaborate terms. Building on insights from information acceleration ${ }^{(38)}$ and construal level theory ${ }^{(16)}$, the present study used systematically varied filmed scenarios to experimentally manipulate five key perceptions of personalised nutrition as important determinants of consumer acceptance: framing, agreement among experts, which stakeholder group benefits, ease of use, and freedom of choice ${ }^{(32)}$. In line with the literature on consumer acceptance of innovations in the food domain ${ }^{(18)}$ the effects of these perceptions on consumer acceptance were hypothesised to be mediated by an identified set of four psychological mechanisms: cost-benefit assessment, perceived risk and uncertainty, perceived behavioural control and the subjective norm.
Overall, the present results provide strong support for the framework developed by Ronteltap et al. ${ }^{(18)}$. Cost-benefit assessment appeared to be the most important construct in this process, followed by perceptions of the subjective norm. To consumers, nutrigenomics applications will only be acceptable if they see a true added value either for themselves or for the advancement of nutritional sciences. This finding deserves particular attention as consumers can be suspicious towards commercial interests of the food industry ${ }^{(11)}$. Furthermore, the relative importance of the subjective norm indicates that personalised nutrition is most likely to be accepted if consumers feel supported by their direct environment to engage in using these applications.

For the more specific consumer perceptions of personalised nutrition, we found that agreement among expert stakeholders, benefits for consumers or scientists, ease of implementation, and freedom of choice contributed positively to consumer acceptance of personalised nutrition. Of these four perceptions, freedom of choice was by far the most important driver of acceptance. This is in line with previous research suggesting consumer concerns about the misuse of genetic 
information ${ }^{(50)}$. Strong support was found for the hypothesised routes through which consumer perceptions affect acceptance. Additionally, many of the effects of consumer perceptions on acceptance were mediated by considerations of costs and benefits. This illustrates once again the importance of nutrigenomics applications to provide clear benefits to the consumer both in the short term (direct advantages to the consumer) or in the longer term from nutrigenomics supporting further scientific progress in the field of diet and health.

The present study identified a number of issues to be taken into account in the further development of nutrigenomics and its spin-offs. Throughout the entire process of development, it is important that expert stakeholders, for example, nutritional scientists, communicate unequivocally about what can realistically be expected from nutrigenomics. Actual spin-off products, for example, personalised advice or food products, must provide a clearly recognisable advantage to the consumer, and should be easy to implement into daily routine. Note, however, that a recent study shows that agreement among experts and easy implementation are considered unlikely by experts ${ }^{(51)}$. Of utmost importance, consumers need to be reassured that making the genetic profile available or using personalised nutrition are options free at their own choice. A supportive communication strategy should be developed to familiarise consumers and their direct environments with personalised nutrition.

Our exploratory consumer segmentation, although not conclusive, showed that consumers differ both in how they value alternative scenarios of personalised nutrition and in the key psychological processes that guide their acceptance. Further research is needed to elaborate on these differences, particularly to understand why ease of use and freedom of choice fulfil such different roles for different groups of people.

Some limitations of the present study need also be addressed. First, the study was conducted in The Netherlands and hence may require further cross-national and cross-cultural validation. Also, the sample of the main study deviated slightly from the Dutch population statistics with an over-representation of the 40-64-year-old age group and a slight under-representation of lower-educated respondents and single-person households. Such deviations are not uncommon, but might impact on the generalisation of the research findings to the general population. Further, as indicated by one of the reviewers, consumer response to personalised nutritional advice might differ depending on the respondent's attitudes towards diet and nutrition as well as current dietary habits. Exploring these differences might be an interesting venue for future research

Second, although the pilot study generally supported the successful operationalisation of the filmed consumer perceptions, the manipulation of framing was less convincing. From the present data it is not clear whether the framing manipulation was unsuccessful, or whether acceptance of personalised nutrition is indeed insensitive to message framing (enhancement of quality of life $v$. disease risk). Future research needs to clarify this. Finally, due to time and effort constraints, all consumers evaluated a fractional factorial design of eight out of forty-eight possible profiles. Although the hold-out samples varied, the set of calibration profiles was identical for all respondents, which may have affected the results. Also, fractional factorial designs allow for the examination of main effects only, and not interaction effects between the consumer perceptions.
Follow-up research might want to focus on these possible interaction effects in more detail.

All in all, this research is one of the first systematic studies into consumer acceptance of nutrigenomics spin-offs. In terms of marketing potential of nutrigenomics, it showed that freedom of choice, clear consumer benefits at reasonable cost and peer support will be key determinants of consumer acceptance. For the successful development of nutrigenomics and its applications, it is important to take these considerations into account at an early stage.

\section{Acknowledgements}

This research was supported by the Netherlands Organisation for Scientific Research (NWO) as part of the programme 'The societal component of genomics research'. There is no conflict of interest that should be disclosed. The study is part A. R.'s $\mathrm{PhD}$ project with J. C. M. vT. and R. J. R. providing supervision.

\section{References}

1. German JB, Yeretzian C \& Watzke HJ (2004) Personalizing foods for health and preference. Food Technol 58, 26-31.

2. Mehrotra I (2004) A perspective on developing and marketing food products to meet individual needs of population segments. Compr Rev Food Sci Food Saf 3, 142-144.

3. Kussman M, Raymond F \& Affolter M (2006) OMICS-driven biomarker discovery in nutrition and health. J Biotechnol 124, $758-787$.

4. Hesketh J, Wybranska I, Dommels Y, King M, Elliott R \& Pico C (2006) Nutrient-gene interactions in benefit-risk analysis. Br J Nutr 95, 1232-1236.

5. Mutch DM, Wahli W \& Williamson G (2005) Nutrigenomics and nutrigenetics: the emerging faces of nutrition. FASEB $J$ 19, $1602-1616$.

6. McPherson JD, Marra M, Hillier L, et al. (2001) A physical map of the human genome. Nature 409, 934-941.

7. Venter JG, Adams MD, Myers EW, et al. (2001) The sequence of the human genome. Science 291, 1304-1351.

8. German JB \& Watzke HJ (2004) Personalizing foods for health and delight. Compr Rev Food Sci Food Saf 3, 145-151.

9. Joost H-G, Gibney MJ, Cashman KD, Görman U, Hesketh JE, Mueller M, van Ommen B, Williams CM \& Mathers JC (2007) Personalised nutrition: status and perspectives. $\mathrm{Br} \mathrm{J}$ Nutr 98, 26-31.

10. Sutton KH (2007) Considerations for the successful development and launch of personalised nutrigenomic foods. Mutat Res 622, 117-121.

11. van Trijp JCM \& Ronteltap A (2007) A marketing and consumer behaviour perspective on personalised nutrition. In Personalized Nutrition: Principles and Applications, pp. 185-204 [FJ Kok, L Bouwman and F Desiere, editors]. Boca Raton, FL: CRC Press.

12. Kutz G (2006) Nutrigenetic Testing - Tests Purchased from Four Web Sites Mislead Consumers. United States Government Accountability Office Report no. GAO-06-977T, 27 July.Washington, DC: United States Government Accountability Office.

13. Burgess MM (2003) Starting on the Right Foot: Public Consultation to Inform Issue Definition in Genome Policy. Report no. DEG 002.Vancouver: W. Maurice Young Centre for Applied Ethics.

14. Frewer LJ (2003) Societal issues and public attitudes towards genetically modified foods. Trends Food Sci Technol 14, $319-332$. 
15. van Kleef E, van Trijp HCM \& Luning P (2005) Consumer research in the early stages of new product development: a critical review of methods and techniques. Food Qual Pref 16, $181-201$.

16. Trope $Y \&$ Liberman N (2000) Temporal construal and time-dependent changes in preference. J Pers Soc Psychol 79, 876-889.

17. Liberman N \& Trope $\mathrm{Y}$ (1998) The role of feasibility and desirability considerations in near and distant future decisions: a test of temporal construal theory. J Pers Soc Psychol 75, $5-18$.

18. Ronteltap A, van Trijp JCM, Renes RJ \& Frewer LJ (2007) Consumer acceptance of technology-based food innovations: lessons for the future of nutrigenomics. Appetite 49, 1-17.

19. Vesanen J (2007) What is personalization? A conceptual framework. Eur J Mark 41, 409-418.

20. Oliver D (2005) The Future of Nutrigenomics - From the Lab to the Dining Room. Report no. SR-889. Palo Alto, CA: Institute for the Future.

21. Castle D (2007) The ethics of personalized nutrition. Agro FOOD Ind Hi-Tech 18, 68-70.

22. Rogers EM (2003) Diffusion of Innovations, 5th ed. New York: Free Press.

23. Levin IP, Schneider SL \& Gaeth GJ (1998) All frames are not created equal: a typology and critical analysis of framing effects. Organ Behav Hum Decis Process 76, 149-188.

24. Einhorn HJ \& Hogarth RM (1985) Ambiguity and uncertainty in probabilistic inference. Psychol Rev 92, 433-461.

25. Dean M \& Shepherd R (2007) Effects of information from sources in conflict and in consensus on perceptions of genetically modified food. Food Qual Pref 18, 460-469.

26. Smithson M (1999) Conflict aversion: preference for ambiguity vs conflict in sources and evidence. Organ Behav Hum Decis Process 79, 179-198.

27. Tornatzky LG \& Klein KJ (1982) Innovation characteristics and innovation adoption-implementation: a meta-analysis of findings. IEEE Trans Eng Manage EM-29, 28-45.

28. Venkatesh V, Morris MG, Davis GB \& Davis FD (2003) User acceptance of information technology: toward a unified view. MIS Q 27, 425-478.

29. Lee Y, Kozar KA \& Larsen KRT (2003) The Technology Acceptance Model: past, present, and future. Commun AIS 12, 1-50.

30. Deci EL \& Ryan RM (2000) The "what" and "why" of goal pursuits: human needs and the self-determination of behavior. Psychol Inq 11, 227-268.

31. Silvia PJ (2006) Reactance and the dynamics of disagreement: multiple paths from threatened freedom to resistance to persuasion. Eur J Soc Psychol 36, 673-685.

32. Ronteltap A, van Trijp JCM \& Renes RJ (2007) Expert views on critical success and failure factors for nutrigenomics. Trends Food Sci Technol 18, 189-200.

33. Starr C (1969) Social benefit versus technological risk. Science 165, $1232-1238$.
34. Fishbein M \& Ajzen I (1975) Belief, Attitude, Intention, and Behavior: An Introduction to Theory and Research. Reading, MA: Addison-Wesley.

35. Rozin P (1999) Food is fundamental, fun, frightening, and far-reaching. Soc Res 66, 9-30.

36. Ajzen I (1991) The theory of planned behavior. Organ Behav Hum Decis Process 50, 179-211.

37. Bagozzi RP, Gopinath M \& Nyer PU (1999) The role of emotions in marketing. J Acad Market Sci 27, 184-206.

38. Urban GL, Weinberg BD \& Hauser JR (1996) Premarket forecasting of really-new products. $J$ Mark 60, 47-60.

39. Green PE \& Srinivasan V (1990) Conjoint analysis in marketing: new developments with implications for research and practice. J Mark 54, 3-19.

40. Wittink DR \& Cattin P (1989) Commercial use of conjoint analysis: an update. $J$ Mark 53, 91-96.

41. Bredahl L (2001) Determinants of consumer attitudes and purchase intentions with regard to genetically modified foods - results of a cross-national survey. J Consum Pol 24, 23-61.

42. Laros FJM (2006) Emotions in consumer research - an application to novel food products. PhD Thesis, Tilburg University.

43. Baron R \& Kenny DA (1986) The moderator-mediator variable distinction in social psychological research: conceptual, strategic, and statistical considerations. J Pers Soc Psychol 51, 1173-1182.

44. Wedel M \& Kamakura W (2000) Market Segmentation - Conceptual and Methodological Foundations, 2nd ed. Dordrecht: Kluwer Academic Publishers.

45. Green PE \& Schaffer CM (1991) Importance weight effects on self-explicated preference models: some empirical findings. Adv Consum Res 18, 476-482.

46. Massoud M, Ragozin H, Schmid G \& Spalding L (2001) The Future of Nutrition: Consumers Engage with Science. Menlo Park, CA: Institute for the Future.

47. Cain M \& Schmid G (2003) From Nutrigenomics Science to Personalised Nutrition: The Market in 2010. Menlo Park, CA: Institute for the Future.

48. International Food Information Foundation (2006) Tailoring Your Diet to Fit Your Genes: A Global Quest. Food Insight Newsletter, January/February 2006. http://www.ific.org/ foodinsight/2006/jf/genesfi106.cfm

49. International Food Information Foundation (2006) Getting Personal with Nutrition. Food Insight Newsletter, November/December 2003. http://www.ific.org/foodinsight/2003/nd/nutritionfi603.cfm

50. Chadwick R (2004) Nutrigenomics, individualism and public health. Proc Nutr Soc 63, 161-166.

51. Ronteltap A, van Trijp JCM \& Renes RJ (2008) Making nutrigenomics work - integrating expert stakeholder opinions and consumer preferences. Trends Food Sci Technol (epublication ahead of print version 6 February 2008).

52. Centraal Bureau voor de Statistiek (2006) Statistisch Jaarboek 2006 (Statistical Yearbook 2006). Voorburg/Heerlen, The Netherlands: CBS (Centraal Bureau voor de Statistiek). 


\section{Appendix 1}

\section{Film scene: message framing}

Many years of nutrition research have taught us a great deal about nutrition and health. This knowledge has, among other things, contributed to our ever-increasing life expectancies.

Positive. Therefore, we continue to live longer. Nutrigenomics can enable us to enjoy our extended lives more, to live in good health as long as possible.

Negative. Therefore, we continue to grow older, and the last years of our lives we often live in poor health. Nutrigenomics can enable us to delay diseases, so we can shorten the time we live with deprivations.

\section{Film scene: agreement}

The last couple of years, the use of nutrigenomics has increased hand over fist; growing numbers of people have had their genes profiled and eat according to a personalised dietary advice. This development will be discussed by two experts in the field of nutrition and health: Mrs A, who is a family doctor and dietary advisor, and $\mathrm{Mr} \mathrm{B}$, who is a professor in health sciences.

Mrs A: 'I am convinced that these diets can contribute to a healthier country. In practice, I experience people feeling better using them; I really see fewer patients. Of course, a lot of scientific research needs to be done to underpin everything, but based on what we know now I think we should stimulate the use of personalised nutrition.'

Consensus. Mr B: 'I totally agree with her. Indeed, not everything has crystallised out yet, but we definitely have a good starting point, and so I think it is wise to continue this way.'

Dissensus. Mr B: 'I totally disagree with her. We are only at the base of scientific research; current hypotheses are not well supported yet. Based on the little information we have now, I don't think we should stimulate the use of personalised nutrition.'

\section{Film scene: which group benefits?}

Understanding how our genes influence the way we digest our food is very important, as it leads to understanding the relationship between nutrition, health, and disease.

Consumer. What has become clear lately is that nutrigenomics delivers many benefits to the consumer. By choosing food products fine-tuned to their genetic profiles, people can prevent certain diseases and gain a large health benefit.

Science. What has become clear lately is that nutrigenomics delivers many benefits to scientists. Because they have a better understanding of how nutrition and genes interact, they can boost research in this genetic field and make a leap forward in science.
Industry. What has become clear lately is that nutrigenomics delivers many benefits to the food industry. By applying the latest insights from nutrigenomics, they can develop new product lines to sell more products.

\section{Film scene: ease of use}

What personalised nutrition entails, concretely, is that you visit one of the research centres once. There, they will draw up dietary advice solely for you, because it is fine-tuned to your genes. Such a diet can help you stay healthy longer, or even prevent diseases.

Easy. Following the diet is easy. You can continue eating the foods you were used to, and additionally everybody will receive a unique supplement to be taken daily during meals. This supplement contains exactly those substances you need in the right doses. This means that all members of a family will be able to eat the same meal.

Complex. Following the diet is not easy. The dietary habits you were used to will have to change. You will have to eat a bit more of one product and a bit less of another. You will also need to use new products that are designed for your genes. This means that all members of a family will have to eat different meals.

\section{Film scene: freedom of choice}

National Centre for Gene Research, district South.

Freedom. Since a couple of months, the government advises to have your genes profiled, because of the importance for public health. In this district, people can pay a visit starting today. In an interview, a representative of the Centre is asked what he expects today:

'I have to tell you, it is very difficult to estimate. This morning was busy for a while, followed by a more quiet period. From centres in other districts that have preceded us, we learned that the number of people paying a visit on the first day is highly variable. But we are prepared for everything; our whole team is on standby to draw tubes of blood quickly when it starts getting busy again.'

Coercion. Since a couple of months, the government obliges people to have their genes profiled, because of the importance for public health. In this district, the blood-drawing period started today. In an interview, a representative of the Centre is being asked what he expects today:

'I have to tell you, it is very difficult to estimate. This morning was busy for a while, followed by a more quiet period. From centres in other districts that have preceded us, we learned that the number of people paying a visit at the first day is highly variable. But as it is obligatory, we are dealing with a large number of people, so we have to be prepared for everything. Our whole team is on standby to draw tubes of blood quickly when it starts getting busy again.' 